\title{
LA VIOLACIÓN ORIGINARIA FENOMENOLOGÍA DEL CUERPO SEXUALMENTE ABUSADO
}

\author{
Marcela Venebra \\ https://orcid.org/0000-0003-3880-8155 \\ Universidad Autónoma del Estado de México \\ https://doi.org/10.15304/ag.40.1.6673
}

\section{Resumen}

La tesis central que desarrolla este artículo es que la violencia sexual es una posibilidad fundada en las condiciones - históricas - constitutivas del cuerpo femenino, esto es, que la violencia sexual en contra de las mujeres es posible por la «disponibilidad» de sus cuerpos. La disponibilidad de los cuerpos como condición de la violación sexual se instaura en tres momentos o fases principales: 1) la determinación histórico-espiritual de la identidad subjetiva femenina como fundada en la materialidad de su cuerpo — en sus especificidad o diferencia reproductiva-; 2) la configuración socialmente ambigua de la diferencia del «yo-puedo femenino» de la reproducción y la sensualidad; y 3) el abuso sexual reafirma la disponibilidad histórico-constitutiva del género de modo tal, que la violación sexúa al género como vulnerable, instituye o añade un significado envolvente de lo femenino como vulnerable. Ser un cuerpo-otro es ser, originariamente, un cuerpo disponible, violable, en esencia, sexualmente vulnerable.

Palabras clave: fenomenología, corporalidad, abuso sexual, vulnerabilidad, disponibilidad.

\begin{abstract}
The central thesis developed in this paper is that sexual violence is a possibility founded in the - historical- constitutive conditions of the female body, which means that sexual
\end{abstract}

Recibido: 17/03/2020. Aceptado: 30/06/2020. 
violence against women is possible because of the availability of their bodies. The availability of the female body as a condition for rape is established in three principal moments: 1) The historical and spiritual determination of the subjective female identity as founded in the materiality of her own body —or her reproductive specificity-. 2) The socially ambiguous configuration of the «femenine-I can» derived from the reproduction/sensuality difference; and, 3) The sexual rape as a reassertion of the gender availability in such a way that the rape sexualizes the gender as vulnerable, establishing or adding a wrapping meaning of feminity as something vulnerable. Being an other-body is being, originally, an available body, violable in essence, sexually vulnerable.

Keywords: phenomenology, corporeality, sexual abuse, vulnerability, availability.

Orneo, Licabas, Medón, Pisenor, Taumante, Mérmeros, Foo, Melaneo, Abane, Astilo, Reto, Caraxo, Vagro, Córito, Drías, Grineo, Demoléon, Lico, Cromis, Díctis, Hélope, Flegreo, Hilas, Ifinoo, Clanis, Dorilas, Cílaro, Eurito... el más cruel de los centauros.

Ovidio. Metamorfosis

\section{Introducción}

En las páginas siguientes ensayo un análisis fenomenológico-histórico —o genético- de la corporalidad femenina, concretamente de la violación sexual, a través de las herramientas conceptuales del análisis husserliano de la historia y la filosofía de la cultura ${ }^{1}$, y el aparato conceptual de la fenomenología de la corporalidad desarrollado en Ideas II. Analizo la violación

${ }^{1}$ Me refiero sobre todo a los análisis de La crisis de las ciencias europeas y el ejercicio de "El origen de la geometría", como textos ejemplares de este tipo de análisis, que pretende dar cuenta de la génesis de sentido de las obras espirituales, de los hechos de la cultura, etc. No se trata de una génesis u origen cronológico, sino experiencial. ¿Cómo se instaura el sentido de lo cultural o espiritual? Esa instauración es lo que constituye el núcleo (o apriori) de la historia. En todo caso, partimos de la consideración de los cuerpos femeninos, del género y la sexuación como instauraciones o constituciones experienciales de sentido, como instituciones originarias. Ver Edmund Husserl, "El origen de la geometría”, en Estudios de filosofía, No. 4. Pontificia Universidad Católica del Perú. Instituto Riva-Agüero, 2000, p. 33-54. Trad. Rosemary Rizo-Patrón de Lerner y Jorge Arce. Original: Beilage III, [Ursprung der Geometrie] zu $\mathbb{S} 9^{\mathrm{a}} 1$, Husserliana VI, pp. 365-386.

Por otro lado, agradezco sinceramente la lectura de los evaluadores de este texto, sus comentarios y señalamientos me han permitido precisar y atar algunos cabos sueltos que han hecho el artículo mucho más asequible y claro. Además de la atenta lectura de los árbitros, agradezco especialmente al profesor Javier San Martín, con quien pude discutir el núcleo antropológico de este texto (paso a paso), a los colegas del Seminario de Fenomenología de la UNED, y al profesor Agustín Serrano de Haro, por sus atentas observaciones a aquella exposición de enero en Madrid, en la que desarrollaba los argumentos centrales de este artículo. 
no como un hecho o conjunto de hechos, sino como un acto instituyente de sentido, que significa o instaura un significado de la corporalidad femenina: su «disponibilidad». La génesis de la disponibilidad parece situarse a nivel de una específica dimensión del yo encarnado: el «yo puedo» (Ideas II, $\mathbb{S}$ 59) femenino que, como veremos, se despliega en una paradójica tensión entre lo voluntario y lo involuntario, que sitúa los cuerpos femeninos como cuerpos disponibles.

La disponibilidad de los cuerpos es la condición a priori del abuso sexual. Los cuerpos se constituyen como disponibles a través de tres fases históricas de su materialidad, es decir, de la institución del significado de su fisiología. La primera fase es la determinación de la identidad femenina a través de la materialidad ${ }^{2}$ esencialmente diferencial de su propio cuerpo: su reproductibilidad o capacidad diferencial en la procreación, como lo vio Françoise Héritier. ${ }^{3}$ El segundo momento estructural o constitutivo de la disponibilidad es la neutralización del «yo-puedo reproductivo» del otro femenino (frente al «absoluto masculino» ${ }^{4}$ ). La configuración identitaria

${ }^{2}$ Es importante destacar aquí mismo que el concepto de «materialidad» que empleo en este estudio es el concepto fenomenológico del Leib-Körper husserliano, que se distingue principalmente del concepto de materialidad corporal puesto en circulación por Judith Butler: "El 'sexo' es una construcción ideal que se materializa obligatoriamente a través del tiempo. Es... un proceso mediante el cual las normas reguladoras materializan el 'sexo y logran tal materialización en virtud de la reiteración reforzada de las normas...”(J. Butler, Cuerpos que importan. Sobre los límites materiales y discursivos del "sexo", Barcelona, Paidós, 2002. Trad. Alcira Bixio). El concepto de materialidad de Butler se cierne entre la comprensión hegeliana y un concepto de naturaleza críticado a principios del siglo XX, el del naturalismo. La materialidad aparece desdibujada tras el sexo, en cuanto concepto, normativa, e ideal regulatorio. En contraparte la materialidad del Leib-Körper es nada más que la carne sintiente y autosintiente, espiritual e intersubjetivamente atravesada, orientada en lo más básico de la sensibilidad y el instinto. La materialidad del cuerpo es la carne espiritualizada o, como veremos, desespiritualizada a través de la violencia. El sexo, por otro lado, es más bien fenomenológicamente descrito como sexuación, es decir, dimensión constitutiva de la concreta personalidad humana.

${ }^{3}$ Me referiré más adelante a la tesis central de Héritier en Masculino / Femenino. El pensamiento de la diferencia. Para Héritier, más que la capacidad diferencial en sí y su constitución para sí desde el cuerpo, lo que científicamente importa es la exposición de los mecanismos (simbólicos o profundos) de la reproducción. En este sentido podría afirmar que este estudio debe mucho al marco conceptual que construye Héritier y que parece el más accesible a una interpretación fenomenológica que, de entrada, considera la violación sexual como uno de esos mecanismos de control de la reproducción, pero que, además, pretende explicar qué ocurre con las categorías cognitivas del género en la víctima.

4 "Él es el Sujeto —afirma Simone de Beauvoir-, él es lo Absoluto; es lo Otro." (S. de Beauvoir, El segundo sexo, México, Penguin, 2012, p. 3) Esta alteridad y lo que aquí llamo «absoluto masculino» abrevan su sentido de esta afirmación de Beauvoir, que aclara 
del «yo puedo» abarca las potencialidades corporales, que se cumplen en la actividad de un "yo-hago» (que en cierto sentido también le antecede ${ }^{5}$ ). El yo puedo moverme y sentirme son condiciones semejantes en todo a la función reproductiva del cuerpo femenino al que, sin embargo, se le extirpa históricamente todo trazo de voluntad. El «yo-puedo-reproducirme» ni siquiera entra en consideración, históricamente, como potencialidad efectiva de un yo. Este último proceso constituye la tercera fase o momento de la constitución de la disponibilidad: el destierro de la dimensión espiritual del cuerpo femenino en la violación sexual.

\section{La esencial materialidad del cuerpo femenino}

Los símbolos arcaicos del cuerpo femenino, sus representaciones e imaginaciones aluden siempre a una materialidad reproductiva: el finísimo hilo que teje el mito en la institución de la simbólica del cuerpo femenino es la «fertilidad $»^{6}$ :

Buscando de dónde podía provenir esta «valencia diferencial de los sexos» —señala Héritier- y cuáles serían los fenómenos tomados en consideración en primer lugar para explicar su presencia universal, he llegado a la conclusión hipotética de que no se trata tanto de una carencia por parte femenina (...) cuanto de la expresión de una

la organización histórica de la personalidad femenina en relación con la primariedad de lo masculino y su función fundamental. La perspectiva de S. de Beauvoir coincide en mucho con el análisis fenomenológico que aquí ensayo, es probable que la mayor diferencia entre los propósitos de Beauvoir y los de este estudio se cierna a nivel de una más básica interrogación no sobre el género o el sexo, sino sobre los modos de constitución del cuerpo violentado. ¿Cómo se inscribe el cuerpo violado en un orden de sentido concreto? El género y el sexo son aquí conceptos fundados no en una ontología, sino en una fenomenología de la corporalidad.

${ }^{5}$ Le antecede en el sentido en que la acción puede fundar nuevas potencialidades del yo. “Primigeniamente el 'yo muevo' , 'yo hago', precede al 'yo puedo hacer'. <Pero> también hay ahora un 'yo puedo' vivenciado, desligado del hacer actual.” E. Husserl, Ideas relativas a una fenomenología pura y una filosofía fenomenológica, Libro II, Investigaciones filosóficas sobre la constitución, México, FCE, 2005, \$59, p. 308. Trad. Antonio Zirión Quijano. En adelante Ideas II.

${ }^{6}$ Esta afirmación tiene una base arqueológica especialmente estudiada desde principios del siglo XX. "Ejemplo elocuente de las representaciones del cuerpo en la prehistoria son las Venus o 'mujeres bonitas'. En estas esculturas de piedra destacan la cadera y el pecho sobre los demás rasgos. La mayoría carece de rostro y las extremidades cuando no son ignoradas sólo se sugieren. Se trata de obras que expresan un gran manejo de las formas. Líneas por lo general curvas definen los cuerpos de las Venus, cuyos rasgos se han asociado con la fertilidad." Beatriz de la Fuente, "La universalidad en las representaciones de la figura humana", Arqueología Mexicana, No. 65, enero-febrero de 2004, pp. 12-15, p. 14. 
voluntad de control de la reproducción por parte de quienes no disponen de este poder tan particular. Lo cual nos lleva a hablar de la procreación. ${ }^{7}$

La fecundidad es el principio que determina la alteridad de lo femenino y su conexión, más bien correspondencia, en el continuum de la naturaleza. ${ }^{8} \mathrm{La}$ fecundidad es una potencia envolvente del sentido entero de la corporalidad femenina, invariable, sobre el que se forjan sus significados histórico-culturales particulares. Los símbolos de la diferencia remiten al sustrato más básico de la fertilidad como vaso conductor de la naturaleza al cuerpo femenino. La fertilidad es lo que hace de los cuerpos femeninos cuerpos naturales, materialmente 'estables'. Lo que constituye la diferencia irreductible del otro-femenino es su correspondencia - o incrustación- en la continuidad viviente de lo natural. El cuerpo femenino es primordialmente un cuerpo fecundo. Una subjetividad encarnada en la naturaleza, que se configura como una extensión consciente de esa materialidad. La identidad del otro femenino se sustancializa en su cuerpo:

La mujer está, pues, solidarizada místicamente con la Tierra; el parto se presenta como una variante, a escala humana, de la fertilidad telúrica. Todas las experiencias religiosas en relación con la fecundidad y el nacimiento tienen una estructura cósmica. La sacralidad de la mujer depende de la santidad de la Tierra. La fecundidad femenina tiene un modelo cósmico: el de la Terra Mater, la Genetrix universal. ${ }^{9}$

La fuerza del mito instituye una estructura de trato sexual y de sexualidad, pero lo hace a través de una profunda comprensión de la materialidad como sustancia de lo femenino, estableciendo en ese centro la diferencia irreductible al género. Quiero decir, que las categorías del género que pautan comportamientos y modos de significar el mundo, orientaciones y tendencias subjetivas, tienen su fondo en una metafísica de la materialidad ${ }^{10}$

${ }^{7}$ Françoise Héritier, Masculino / Femenino. El pensamiento de la diferencia, Barcelona, Ariel, 1996, p. 24. Trad. Vicente Villacampa.

${ }^{8}$ Eliade muestra este hilo simbólico de continuidad a través de tres elementos fundamentales en casi toda cosmología: la luna, las mujeres y la fecundidad. La luna representa la naturaleza y toda su rítmica reproductiva, es el poder que rige de los ciclos acuáticos, oceánicos, etc., y con ello los ciclos reproductivos de los animales, los ritmos estacionales, etc. Representa el principio de cambio, mutación, acabamiento y renacimiento que organiza el mundo entorno, todos los elementos no-humanos. El cuerpo femenino se inserta en este continuum a través del rasgo más visible de los ciclos reproductivos humanos: el ciclo menstrual. En primer lugar, sus lazos con las mujeres y la fecundidad: "La luna es fuente de toda fertilidad y gobierna al mismo tiempo el ciclo menstrual. Personificada, se convierte en el 'amo de las mujeres'”. M. Eliade, Tratado de historia de las religiones, México, Biblioteca Era, 2001. Trad. Tomás Segovia.

${ }^{9}$ M. Eliade, Lo sagrado y lo profano, Barcelona, Paidós, 1998, p. 107.

${ }^{10}$ Françoise Héritier se refiere a esto como los sistemas de clasificación o la lógica clasificatoria de las sociedades tradicionales, que sostiene la estructura cognitiva de las categorías 
como reproductiva, y de la reproductividad como determinante material de lo femenino. El otro-femenino es corporalidad, es cuerpo en el sentido de la materialidad anímica de la naturaleza, con particularidades ambiguas dentro de ese mismo entorno. Lo salvaje, lo silvestre e incivilizado no está exactamente asociado a lo femenino, sino que lo femenino en cuanto cuerpo es simbólicamente constituido como una extensión humana —enigmática- de la fuerza productiva y reproductiva de la naturaleza en sí misma. ${ }^{11}$

En el orden antropológico, entonces, el género es algo que se 'gana' o se construye, es cierto, pero la base de las representaciones discursivas es material, es la materialidad productora del cuerpo fértil. Los cuerpos no fértiles son cuerpos ambiguos o marcados por una diferencia que en su tensión logra - $\mathrm{O}$ no- integrarse en un horizonte de significados culturales de modo implícito o explícito. ${ }^{12} \mathrm{El}$ otro femenino es un cuerpo cuyo género se alcanza, se "cumple" en la plenificación de potencias físicas y fisiológicas concretas. ${ }^{13}$ La identidad femenina se funda en la unidad funcional de su cuerpo vivo. El otro-femenino ${ }^{14}$ es su cuerpo de un modo determinante que

de género: "Las categorías de género, las representaciones de la persona sexuada, el reparto de las tareas tal como las conocemos en las sociedades occidentales, no son fenómenos de valor universal generados por una naturaleza biológica común, sino construcciones culturales. Con un mismo alfabeto simbólico universal, anclado en esta naturaleza biológica común, cada sociedad elabora de hecho frases culturales singulares que le son propias.” (F. Héritier, op. cit., p. 20). En términos fenomenológicos ese "anclaje" es lo que debe aclararse, porque el concepto de naturaleza con el que la antropología funciona se opone en ese mismo orden clasificatorio, a lo humano. Fenomenológicamente la naturaleza y, concretamente, la materialidad natural del cuerpo, la carne, es desde su base instintiva intersubjetiva, espiritual y experiencialmente orientada. Es seguramente en este punto, donde cabe inyectar sangre fenomenológica en las venas levistraussianas.

11 "El alumbramiento y el parto son las versiones microcósmicas de un acto ejemplar ejecutado por la Tierra; la madre humana no hace sino imitar o repetir este acto primordial de la aparición de la vida en el seno de la Tierra." Ibíd., p. 105.

${ }^{12}$ Nos referimos a la presencia de terceros o cuartos géneros en sociedades tradicionales. El ejemplo más a mano con el que contamos, sobre esta asimilación explícita es el de los muxe de Oaxaca. Ver Marinella Miano Borruso, Hombre, mujer y muxe' en el Istmo de Tehuantepec, México, CONACULTA-INAH-Plaza y Valdés, 2002. El muxe se define en este sentido como un tercer género que no se corresponde ni con lo femenino ni con lo masculino aunque posee atributos simbólicos y materiales de ambos géneros.

${ }^{13} \mathrm{~F}$. Héritier trata de localizar las expresiones de este régimen de sentido en las inscripciones simbólicas de la corporalidad y sus fluidos, así por ejemplo, afirma que: "La inferioridad intelectual femenina se postula de entrada, sin mayores indagaciones: no hay simiente, no hay gérmenes, no hay ideas, remitiéndose así, sin tener que elaborarla conceptualmente, a la noción casi universal de una continuidad entre la materia cerebral y la materia seminal." F. Héritier, op. cit., p. 9.

${ }^{14}$ Empleo este término a partir del estudio de las alteridades diferenciales, de Javier San Martín en "La fenomenología y el otro". En este ensayo San Martín desarrolla —con 
no coincide con las fuentes definitorias de la identidad del cuerpo masculino. Lo masculino se identifica entre y con sus pares, el otro femenino tiene como centro de referencia sustancial su propio cuerpo - en el cumplimiento de sus funciones orgánicas diferenciales: la fertilidad.

El reconocimiento de lo femenino pende del cumplimiento de su función material, esto es, no se reconoce a la persona, sino el cuerpo, el triunfo de un principio natural que se continúa exitosamente en un momento suyo: el cuerpo-otro. La simbólica del género hace de la fuerza masculina —en su simiente- una potencia transformadora, y productora (incluso respecto de la configuración pasiva y receptora de lo femenino ${ }^{15}$ ). La praxis transformadora ya no es, sin embargo, impulsada por la naturaleza sino por el yo, por la voluntad de un sujeto que, lejos de reducirse a su cuerpo, se individualiza en la transformación de la materia. Como si la profundidad y grandeza de sus transformaciones (la naturaleza en la que se hace una casa) fuese, al mismo tiempo, la indicación de un mayor distanciamiento de la naturaleza, o de un distanciamiento que se convierte a veces en dominio, dominación incluso del cuerpo propio. El reconocimiento masculino de una identidad personal se funda en el cumplimiento de su potencia transformadora y productora, laboral, que le agencia su autonomía y, al mismo tiempo, su participación en la comunidad política.

especial naturalidad- uno de los aspectos a los que le dedicaremos mayor atención más adelante, la sexuación. San Martín pone sobre la mesa el problema a partir de la consideración del tema mismo de la fenomenología. Si el tema del trascendentalismo es la vida la vida subjetiva, y si esa vida subjetiva es vida encarnada, entonces esa subjetividad es ya siempre una subjetividad sexuada, y de esta dimensión podemos dar cuenta, igual que de todo el proceso constitutivo del mundo espiritual, con los instrumentos mismos de la fenomenología trascendental. "No se puede olvidar nunca en la fenomenología que lo que el fenomenólogo trata de describir es la vida humana tal como ésta es o tal como ésta se presenta. Y si en un momento pudo haber dado preferencia a lo teórico, el propio análisis de la vida en su propia manifestación supera esa estrechez, porque la vida real, encarnada en la diferencia sexual y que se desarrolla en el contexto familiar, rompe ese molde de la subjetividad teórica.” J. San Martín, "La fenomenología y el otro. La fenomenología encarando al siglo XXI" en Acta Mexicana de Fenomenología. Revista de investigación filosófica y científica, CEMIF, No. 1., 2015.

15 "El discurso aristotélico opone lo masculino y lo femenino como respectivamente cálido y frío, animado e inerte, soplo y materia. Pero si tomamos ejemplos más recientes (...) podemos mostrar la permanencia, formulada o implícita, de estos sistemas de categorías de oposición (...) El encuentro entre el óvulo y el espermatozoide, lo presentan unos biólogos como el encuentro de una materia inerte, vegetativa, que precisa de ser animada por un principio activo, por una energía que aporta vida.” (F. Héritier, op. cit., p. 19-20). Simone de Beauvoir recupera otra perspectiva de esta misma lógica: "La idea que expresa Aristóteles: la mujer es solamente materia, «el principio del movimiento, que es masculino en todos los seres que nacen, es mejor y más divino» (...) el hombre se desprende de la influencia de la feminidad y conquista contra la mujer la dominación del mundo.” S. de Beauvoir, op. cit., p. 31. 
El cuerpo masculino se re-laciona con la naturaleza, frente al cuerpo femenino que el mito 'clasifica' EN el orden de la naturaleza, encarnación de la fuerza reproductiva de la naturaleza. El cuerpo femenino no transforma la naturaleza, es naturaleza que se transforma ella misma con aparente autosuficiencia en la procreación. El otro-femenino se significa a partir de su materialidad y la normalidad de su estructura funcional o procreadora. Si la persona humana es la unidad anímico-espiritual capaz de autosensibilidad, autodeterminación, y transformación de su entorno, el otro-femenino es unidad anímica cuyo carácter espiritual se mantiene en una relación tensa respecto de la marca siempre visible de su diferencia corporal.

La fertilidad del cuerpo femenino se asocia históricamente a un estrato o nivel impulsivo, en el que el gobierno del instinto es lo opuesto del autogobierno, lo que conduce a una paradoja en la constitución de su identidad personal. Y es que la identidad personal es en esencia la concreción individualizante de la vida subjetiva en y con otros. Esa identidad egoica es corporal, pero es también vida espiritual no determinada por la materialidad del cuerpo en algún punto. Decimos que la persona es su cuerpo, pero además tiene un cuerpo y es más que su cuerpo, es su biografía, sus relaciones, sus proyectos, etc., aspectos todos irreductibles entre sí. La persona es sujeto de capacidades ${ }^{16}$ que se sabe en un mundo que es, para cada uno, referencia de sentido y orientación, dónde y hacia dónde de la experiencia. La sujeción de la identidad de lo femenino a la materialidad de su cuerpo hace que tal concreción sea, en el cuerpo otro, el cumplimiento de la más pasiva y abstracta de sus determinaciones. Como decir que el otro femenino, para llegar a ser, tiene que conformarse con lo que es.

Luigi Zoja propone una interpretación de la identidad femenina como mucho más «estable» ${ }^{17}$ que la identidad masculina y, por ello, menos problemática a la hora de estudiar fenómenos como la violencia sexual. Esto quiere decir que la violencia sexual sería mucho menos un problema femenino que un asunto crítico en relación con la conformación histórica de la

16 "El yo espiritual puede así ser aprehendido como un organismo, un ORGANISMO DE CAPACIDADES (...) LA CAPACIDAD NO ES UN PODER VACío, SINO UNA POTENCIALIDAD POSITIVA que viene en cada caso a actualización, está siempre en disposición de pasar a la acción que, en tanto que es vivencial, remite al poder subjetivo inherente, a la capacidad." E. Husserl, Ideas II, $\mathbb{5} 59$, p. 302.

17 "A lo largo de la evolución natural, la identidad femenina permanece relativamente estable: cuando comienza a aparecer una sociedad ya no animal sino humana, en las mujeres la biología y la cultura se funden en un papel aceptado y poco contradictorio." L. Zoja, Los centauros. Los orígenes de la violencia masculina, México, FCE, 2018. 
masculinidad. Zoja descarta el problema de la feminidad ${ }^{18}$ a través de la postulación de una mayor estabilidad identitaria, y se permite seguir adelante en el estudio de la personalidad masculina, cuyo precario equilibrio sería el factor detrás de conductas sociopáticas como la violación. En una ecuación que correlaciona, a través de la contención, la presencia de un poder político con la fuerza instintiva de lo masculino - arraigado en el modelo de una sociedad mítica de machos-, Zoja propone que la violación es una tendencia latente en la constitución de lo masculino, que siempre puede ser atizada por condiciones políticas inestables.

El símbolo de la identidad masculina es, para el psicoanalista, el centauro (y el relato mítico que lo soporta); una idea de masculinidad como el resultado inacabado de una hibridación entre el plano natural y el mundo civilizado. El centauro no ha acabado de ser, en verdad, ninguna de las dos cosas. Quirón es la culminación irredenta del costado humano de la manada pre-civilizada. El centauro se decanta siempre por su costado animal, se deja envolver en él cuando se embriaga, y el culmen de la ebriedad es la violación tumultuaria. El crimen del centauro no alcanza en el perpetrador, por su naturaleza colectiva — según Zoja— la categoría de crimen, o permanece para el victimario en una zona gris, determinada por la naturaleza del acto en el que la transgresión se convierte en la regla del grupo, la única regla. La ebriedad supone una permisión colectiva, un consenso implícito sobre la transgresión humorística y violenta de la norma. La ebriedad representa el momento de flexibilización colectiva - y por lo tanto anónima- de la norma, igual que en la guerra, esa circunstancia detona en un grupo acéfalo de hombres la captación de estas posibilidades, el acceso violento al cuerpo femenino (como botín y bandera) como modo de instauración de un orden sobre la propiedad arrebatada a otro. El modelo del psicoanalista es sin duda útil para la descripción de la instrumentación de la violación como arma de guerra, pues nos permite incorporar un cierto perfil del violador y, desde luego, identificar las situaciones donde la violación colectiva se detona típicamente como instrumento de control por la violencia. Pero de modo aún más útil, nos revela, esta lectura de Zoja, elementos clarificantes sobre la constitución de la «inestabilidad» de la identidad masculina.

La inestabilidad de la identidad masculina estaría así determinada por una hibridación desequilibrada entre naturaleza y espíritu. Como decir que el macho humano es el responsable y creador de la civilización sin que por

${ }^{18}$ Entiéndase aquí como sentido constitutivo de un cuerpo reproductivamente diferenciado. 
ello haya podido desprenderse plenamente, catalizar o domesticar sus instintos e impulsos más básicos. Un sustrato de sensibilidad, por así decir, silvestre o salvaje, permanece latente, como un reducto arcaico que amenaza continuamente su contra-polo racional. Desde el punto de vista de Zoja, el síndrome del centauro explica la presencia continua del abuso sexual en sociedades civilizadas, o mundos culturales donde el mito ha logrado reprimir sin aniquilar el impulso 'natural' del hombre que en situaciones políticamente inestables vuelve a emerger con toda su fuerza física y psíquica, imponiéndose sobre toda posibilidad constitutiva del cuerpo femenino. Respecto del centauro, lo femenino no es híbrido sino estable, en el sentido de no participar de la espiritualidad, de ser un cuerpo, pura, o meramente material.

También es discutible que sea el instinto masculino y no su condición espiritual, racional, la que detone la agresión, esa idea centáurica de sí mismo, las representaciones de la masculinidad como instintiva, etc. Según Zoja la brida impuesta por la comunidad al impulso masculino es la generación de la paternidad como una marca o delimitación histórica y espiritualmente constituida de la masculinidad occidental. Desde esta perspectiva la gestación, el parto y la crianza (amamantar), serían más bien dimensiones instintivas del cuerpo femenino, más allá o más acá de todo marcaje espiritual, histórico o cultural. Para Zoja la paternidad constituiría una primera limitante social del estupro. Aunque habría que ver que tal limitación se produce ya en un marco de ordenación social, el parentesco o la territorialidad. La ley instituyente (o sagrada) no prohíbe la violación, prohíbe violar a las mujeres 'de' algunos. Se trata de una marca producida sobre una disponibilidad ya dada como condición, como la determinación de su materialidad específica, ser accesible a algunos, de diferentes modos.

La estabilidad de la identidad femenina, así pensada, no sería sino la representación histórica de la fertilidad, transfigurada en una estructura pasiva, poco problemática (hasta ahora por lo menos), fundada en un núcleo material pre-egoico, pre-reflexivo, y en los márgenes de toda o de cualquier acción del yo.

Los cuerpos femeninos, dicho de otra forma, son cuerpos violables por razón de esa estabilidad, es decir, de su pertenencia visible y determinada en el orden de la naturaleza, por la esencia material de su propio cuerpo. La propiedad, es decir, la dimensión egoica o yoica del cuerpo femenino, permanece en una región opaca, más bien ambigua, pues la reproducción, como veremos, es la marca central de la estabilidad y no es ella misma constituida como una posibilidad del yo sexuado, sino como una necesidad funcional de su cuerpo. 
El cuerpo femenino es constituido, en esta diferencia, originariamente como órgano de reproducción y recurso material. Esto es lo que posibilita su movilización como medio de intercambio. Los cuerpos femeninos son intercambiables — siguiendo la lógica de Lévi-Strauss- porque están ahí disponibles, al igual que los mensajes y los bienes (territoriales), como lo está la naturaleza, igualmente disponible para su transformación, como campo de labor; y, en segundo término, porque al igual que los mensajes y los bienes son reproducibles. Esta es la condición que regula el matrimonio y, con ello, el parentesco. ${ }^{19}$

Tal disponibilidad demanda una enajenación o vaciamiento de la voluntad del cuerpo en aquellas potencias concretas que le distinguen, como potencias que la violencia explota ${ }^{20}$. La disponibilidad de los cuerpos implica la negación de esa esfera espiritual asociada a lo masculino como fuente de desequilibrio, que comienza en una alienación de la voluntad sobre la diferencia material de su propio cuerpo.

\section{La voluntad negada. El «yo puedo» femenino}

El yo puedo es centro o núcleo constitutivo de la corporalidad: "El yo como unidad es un sistema del 'yo puedo'. Aquí hay que diferenciar entre el 'YO PUEDO' FísICO, el corporal y el corporalmente mediado, y el ESPIRITUAL. Yo tengo dominio sobre mi cuerpo, yo soy quien mueve y puede mover esa mano, etc." ${ }^{21}$ Según Husserl, el yo puedo físico se dice corporalmente 'mediado', por una distinción entre el yo (aquí como potencia activa) y el cuerpo en su materialidad autónoma, una autonomía cinética - por ejemplo- que es 'del' yo encarnado. El yo puedo espiritual es la persona concreta y auto-reflexiva, es un sujeto de capacidades adquiridas. El yo adquiere y desarrolla capacidades en su trato con los otros. Hay un yo puedo espiritual que incluye las potencialidades activas de la persona en su circunstancia intelectual, moral, económica, etc. Adquirimos capacidades

19 “A los tres pilares que para Lévi-Strauss eran la prohibición del incesto, el reparto sexual de las tareas y una forma reconocida de unión sexual, añadiré un cuero, tan evidente que no se advertía, pero absolutamente indispensable para pensar el funcionamiento de los otros tres (...) la valencia diferencial de los sexos." (F. Héritier, op. cit., p. 26. El contenido de la valencia diferencial de los sexos es propuesto aquí como la diferencia-reproductiva del cuerpo-otro.

${ }^{20}$ Ver D. Bergoffen, "Exploiting the Dignity of the Vulnerable Body: Rape as a Weapon of War” en M. Staudigl, Phenomenologies of Violence, Leiden-Boston, Brill, 2014.

${ }^{21}$ E. Husserl, Ideas II, $\mathbb{S} 59$, p. 301. 
en el trato con los otros, significamos nuestras potencialidades propias en el trato interpersonal, ${ }^{22}$ como decir que el movimiento es una potencia espontánea del cuerpo propio, mientras danzar, bailar, es una capacidad adquirida. Las capacidades espirituales, en tal caso, inciden, moldean, significan las capacidades inmediatas. La persona espiritual es concreción de estas capacidades, habitualidades adquiridas e intersubjetivas, en su horizonte de posibilidades.

La carne está siempre espiritualmente traspasada, el impulso y el instinto no son solo moderados por el entorno interpersonal, sino que tienen un sentido para el sujeto que los vive, cobran una incidencia específica en la constitución de la personalidad. ${ }^{23} \mathrm{La}$ materialidad carnal del cuerpo en su condición sintiente y autosintiente tiene una dimensión o determinación espiritual concreta. Aun el sustrato impulsivo e instintivo 'se forja' y se perfila bajo estilísticas intersubjetivamente configuradas. Fenomenológicamente, la «sexuación» puede entenderse como el proceso constitutivo de ciertos modos comprensivos de la experiencia del propio cuerpo, consistente en la identificación de significados asociados a la materialidad del cuerpo con pautas de comportamiento y funciones sociales específicas. Es posible pensar que la sexuación sea, desde este punto de vista, un proceso enfáticamente constituyente del cuerpo femenino, tanto más que del masculino, y esto por razón de su referencia reproductiva. Las pautas de comportamiento que se traducen en restricciones están, en el caso de la sexuación femenina, basadas en el control de su cuerpo de manera mucho más visible que en el caso de los varones, lo que determina su función comunitaria - casi en el sentido de un recurso natural.

22 "El desarrollo de una personalidad está determinado por la influencia de otra, por la influencia de pensamientos ajenos, de sentimientos ajenos sugeridos, de órdenes ajenas. La influencia determina el desarrollo personal.” E. Husserl, Ideas II, $\mathbb{S} 60$, p. 316.

${ }^{23}$ Ibíd., p. 317. Es importante destacar que este concepto de carne, aunque cercano, quizás a Merleau-Ponty, al menos por una línea histórica visible, se distingue en este análisis de manera global por su carácter constituido en relación con la unidad estesiológica del cuerpo propio. La fenomenología husserliana de la corporalidad, que aquí funciona como base, se despliega a través de los planos de constitución del cuerpo, del cuerpo como fenómeno y cosa en el mundo, como se da, como aparece, como se constituye. La carne espiritualmente traspasada se ubica en ese mismo plano de la constitución del mundo que, en última instancia, Merleau Ponty pretende radicalizar a través de la subjetivación del cuerpo en que se despliega su análisis de la percepción, por ejemplo. Por otro lado, el interés de este ensayo radica, sobre todo, en la movilización del aparato husserliano, y de esa cepa del análisis fenomenológico de la constitución que las ontologías del cuerpo marginaron en busca de una mayor radicalidad, de la carne autosintiente y la esfera pre-egoica, etc. (que veremos aparecer en el análisis husserliano más cercano a la historia). 
La potencia reproductiva diferencial del cuerpo femenino es tanto una potencia espontánea o constitutiva del cuerpo propio, como una capacidad adquirida espiritualmente. "Hay un instintivo amor materno" ${ }^{24}$ afirma Husserl, tanto como un amor paternal instintivo. El instinto funciona aquí como tendencia originaria; un tender-hacia por motivos que rigen al yo sin que el yo se domine a sí mismo. No se trata pues, del instinto como inscripción orgánico-material sino de un núcleo de sensibilidad pasiva que, de cualquier modo, está intersubjetivamente orientada, mediada, reglada. "Tenemos tendencias — según Husserl— que rigen al yo hago, yo padezco y fuerzas que le dan reglas. Por otro, tendencias de conciencia que caracterizan subsiguientemente a estos actos, y al yo". ${ }^{25}$ Tales tendencias están intersubjetiva o habitualmente prefiguradas y detonadas, de tal modo que entre tales tendencias y la vigilia se concreta el yo "libre y subyugado", afirma Husserl.

El 'desarrollo' del yo alude a los estratos que constituyen su unidad, podemos distinguir dos polos de esta misma estructura: un polo de actividad y otro de pasividad con relación a la posición o disposición del yo, ya sea llevado 'mecánicamente' por el instinto o el hábito; o bien actuante en vigilia y opuesto, resistente al impulso. ${ }^{26}$ Esta estructura, por así decir, estratigráfica de la corporalidad, nos permite dar cuenta de la constitución de la capacidad diferencial del cuerpo femenino, entre el yo puedo físico activo, el yo dormido o pasivo, y el yo puedo espiritual, como una capacidad significada históricamente. ${ }^{27}$

${ }^{24}$ E. Husserl, "El espíritu común, I y II (1921). Obra póstuma”, en: Themata. Revista de Filosofía, Universidad de Sevilla, No. 4., 1987, p. 135 / 166.

${ }^{25}$ Husserl, Ideas II, $\mathbb{S} 59$.

26 "La afección pertenece sin duda a la esfera de la naturaleza y es el medio del enlace del yo y la naturaleza. El yo tiene también su lado de naturaleza (...) Pero en el mejor de los casos es el yo pensado de modo puramente pasivo el que es mera naturaleza y pertenece al nexo de la naturaleza. Pero no el yo de la libertad (...). Mera naturaleza — dice Husserl—es todo "yo-hago mecánico"” (E. Husserl, Ideas II, Anexo XII, $\mathbb{S} 3$, p. 390). En esta distinción husserliana el yo-hago-mecánico es el que cede al impulso, el yo en vigilia puede resistir al impulso por motivos de razón, o por hábitos fundados en motivos de razón. El yo libre no solo se ve arrastrado por sus tendencias básicas o por la afección, no es mera naturaleza, sino que pondera, valora sus motivos, tiene sus fines conforme a los cuales opone resistencia a la pasividad del impulso.

${ }^{27}$ Desde luego nos referimos siempre al mismo idéntico yo, visto desde diferentes posiciones o disposiciones. El yo puro es el polo unificante de la corriente de vivencias, pero ese yo idéntico es al mismo tiempo conciencia encarnada, sujeto encarnado de hábitos encarnados, etc. Los hábitos son del yo, pero de una subjetividad corporalmente constituyente. "Pertenece, pues, a lo mío propio (en cuanto purificado de todo sentido de otra subjetividad) 
El yo puedo moverme es una capacidad del yo mediada por el cuerpo: "Y estas cinestesias de los órganos transcurren en el 'lo hago yo' y están sometidas a mi 'yo puedo'." ${ }^{28}$ Pero es posible preguntar ¿qué significa un "yo puedo gestar»?; esta es una potencialidad mía mediada por el cuerpo, sólo mía en cuanto cuerpo sexuado, de esta y no de otra manera, es decir, en cuanto cuerpo femenino. El yo-puedo-gestar es entonces, al igual que otras capacidades físicas una potencía mía, efectivamente sometida, como toda potencia corporal a mi 'yo puedo'. La gestación como potencia de un yo encarnado es entonces algo que puedo o no hacer con mi cuerpo, como otras capacidades espirituales o adquiridas.

Como potencialidad del yo, y en un sentido negativo, es esta potencialidad diferencial del cuerpo femenino la que busca destruir la violación sexual: la capacidad sensual o de sentir placer, y la esfera constitutiva concreta de lo femenino. Esta destrucción es posible, como hemos visto, por la disponibilidad estructural de la carne femenina, cuyo factor determinante es la negación histórica de la voluntad del yo sexuado por la materialización, o naturalización (o estabilización) de la identidad femenina. La configuración histórica de estas potencialidades implica una negación de la incidencia de la voluntad en el cumplimiento de las funciones que se consideran "naturales”, instintivas en un sentido orgánico determinista. El análisis fenomenológico nos permite ver que el yo puedo reproducirme, o yo puedo gestar, yo puedo amamantar, etc., son potencias tan espontáneas como espirituales o personalmente prefiguradas. La orientación histórico-material de estas "tendencias" corporales, del instinto materno (durante la gestación por ejemplo) las inscribe en un orden más bien meramente pasivo, de un yo dormido, un cuerpo que 'mecánicamente' cumple su función. Y, sin embargo,

Los nexos de motivación (...) están determinados por los niveles sensibles inferiores, pero tienen su ley propia. Ninguna motivación de yo activa se origina por "asociación" y por "legalidad psicofísica", o sea, no se origina como lo hacen todas las formaciones de la sensibilidad. Está presupuesto, sin embargo, el engranaje entero de la naturaleza, el "mecanismo de la "naturaleza". ¿Puede decirse ahora que lo que parte del yo o en el yo ocurre como "afectar", penetrar en el yo motivando, tirar de él hacía sí cada vez más vigorosamente — todavía antes del ceder-, no es ya naturaleza?29

un sentido de 'mera naturaleza' que ha perdido también incluso este 'para cualquiera' (...) Entre los cuerpos propiamente captados de esta naturaleza, encuentro luego, señalado de un modo único, mi cuerpo vivo, a saber; como el único que no es mero cuerpo físico, sino precisamente cuerpo vivo.” E. Husserl, Meditaciones cartesianas, México, FCE, 2005. "Quinta meditación”, $\mathbb{4} 44$, p. 143. Trad. Miguel García Baró.

${ }^{28}$ Ídem.

${ }^{29}$ E. Husserl, Ideas II, Anexo XII, $\mathbb{3}$ 3, p. 391. 
No - responde Husserl- lo que toca al yo no es ya naturaleza. Todo acto del yo tiene su cola de cometa, su estela en la naturaleza, pero no se explica ni se reduce a la organicidad funcionante — causal- del cuerpo. El problema respecto de la constitución histórica de los cuerpos femeninos, de su diferencia reproductiva, estriba en su absoluta inclusión en el plano pasivo, como un mero afectar de un yo dormido.

Si el núcleo de la identidad femenina es la materialidad 'estable' de su propio cuerpo, su falta de espíritu, esta carencia constitutiva de la historicidad de lo femenino retrae la capacidad o potencia diferencial del cuerpootro al plano de la instintividad orgánica más allá de toda voluntad, o de todo "yo" como polo de actividad, yo en vigilia, yo de las valoraciones. Si en términos fenomenológicos el yo de los actos es un yo de la voluntad mediatizada por el cuerpo, en todo lo referente al desarrollo reproductivo de las mujeres acontece una relación inversa, en la cual, es el despliegue (desarrollo) del cuerpo lo que media la realización del yo. El cuerpo, pues, cobra independencia en las representaciones espirituales de la gestación y los procesos 'naturales' del cuerpo-otro. En estos 'procesos'no se trata del yo realizando una acción corporal, sino del cuerpo realizando al yo a través de su cumplimiento 'funcional'. La gestación no es un acto del yo (este es el núcleo de sentido histórico de la diferencia reproductiva del cuerpo-otro), quiero decir que la gestación como proceso biológico se mantiene, discursivamente, en una esfera separada respecto del yo. Y sin embargo, gestar es es una acción que alguien, un yo, "realiza".

El «yo puedo gestar» es una potencia egoica, es un yo-puedo físico en primera instancia y espiritual en segundo término. La estructura sedimentaria de la experiencia hace que las capas superiores de sentido, es decir, las significaciones espirituales, inclinen, orienten y prefiguren en cierto modo el instinto. Del mismo modo que la sedimentación de arena en un banco, modifica la posición de las primeras capas. El instinto y los datos del instinto que corresponde a la sensibilidad primaria quedan envueltos, por así decir, en las capas superiores de la sensibilidad espiritual o impropia. ${ }^{30}$

La corporalidad femenina y su capacidad diferencial pertenecen experiencialmente a ambos planos, porque la materialidad está ya siempre espiritualmente 'cargada', traspasada, significada; porque los estados de la

30 “Distinguimos aquí SENSIBILIDAd y (decimos) RAzón. En la sensibilidad distinguimos la protosensibilidad, que no contiene nada de sedimentos de la razón, y la sensibilidad secundaria, que nace de una producción de la razón. En conformidad con ello dividimos también la razón en RAZÓN PRIMIGENIA, INTELLECTUS AGENS, y razón sumergida en sensibilidad” E. Husserl, Ideas II, Anexo XII, $\mathbb{1}$ 1, p. 386. 
carne orientan también estados anímicos (el dolor), y porque el cuerpo es una cosa viva en el mundo de las cosas vivas, en la realidad física: "Mi mano también es una cosa, y cuando yo ejecuto un 'yo muevo' subjetivo y no sueño ni me engaño, entonces también en la naturaleza se lleva a cabo un proceso físico." ${ }^{11}$ Esto quiere decir que los actos del yo pertenecen tan a la naturaleza como al yo, pero no se reducen mutuamente. La gestación y el parto son procesos biológicos desatados por una voluntad yoica, fundada en una capacidad corporalmente mediada. El «yo puedo» es la distancia entre el proceso físico y la vida de la conciencia como ya no causalmente determinada. Los actos del yo no responden a causaciones sino a motivaciones, aun los actos de su voluntad mediada por su cuerpo.

Sin embargo, el yo me muevo, yo puedo sentir el roce del viento en mi rostro, yo hago, no coinciden históricamente con un «yo puedo gestar». La potencialidad reproductiva del cuerpo femenino se configura (por una mediación del discurso mítico, primero, y médico, después) como función de la naturaleza al igual que el movimiento, pero mecánica como la respiración. La fertilidad se considera más bien una potencia necesaria independiente del yo y se tematiza como materialidad orgánica y funcional. Y es que si digo yo-puedo, ese yo que mienta una potencia suya es, como subjetividad encarnada, un yo sexuado, por lo que toda potencia del cuerpo parece traspasada por la condición material desde la que se constituye la persona para sí en la auto-reflexión. ${ }^{32}$

El Yo-puedo-femenino de la reproducción es el fondo central de las posibilidades de constitución identitaria del sujeto sexuado. Yo puedo: reproducirme, gestar, parir, alimentar otro cuerpo, son potencialidades originarias de lo femenino que se presentan en el limen de la posibilidad y la necesidad. Es significativo que el primer nombre del parto sea "labor" y que el significado de la labor sea pre-humano, natural como necesario. ${ }^{33}$ Todo acto del

${ }^{31}$ Ibid., p. 308.

32 "Uno de los elementos estelares [en la fenomenología] es la encarnación, el hecho de que nuestra realidad primordial es nuestro cuerpo. Desde ese momento el ser sexuado es la condición del ser humano y en esa misma medida el género en sus diversas versiones entra como uno de los temas de la fenomenología. Si, además, esa situación afecta tanto a la constitución en general del sujeto, como a la organización misma de la vida, la condición sexuada del ser humano es, sin lugar a duda, uno de los ejes fundamentales de la reflexión fenomenológica.” J. San Martín, art. cit., p. 151.

33 "La labor se consideraba la suprema capacidad del hombre para constituir el mundo (...) la labor es la más natural y menos mundana de las actividades del hombre.” (Hannah Arendt, La condición humana, Barcelona, Paidós, 2016, p. 114). Arendt localiza en esta consideración histórica la raíz de la confusión entre trabajo y labor que aquí no nos atañe, pero que desde su punto de vista, es ya en sí misma una patente contradicción. 
yo, todo yo hago tiene su "cola de cometa en la naturaleza" ${ }^{34}$, pero no es ya naturaleza, es decir, la acción humana no se inserta en el flujo causal de la necesidad natural, el poder de la voluntad abre la dimensión experiencial de la posibilidad, o bien de la libertad. Pero lo que aquí importa es la estela, la naturaleza, el modo en el que se comprende la naturaleza es ya una vinculación, un modo de relación que incide en la constitución histórica de lo humano. El yo puedo del cuerpo femenino implica una potencia productora diferencial y, sin embargo, la reproducción del cuerpo femenino no se constituye históricamente como un "yo puedo» en el sentido en que lo es el desplazamiento de los cuerpos y entre los cuerpos; no lo es, tampoco, en el sentido de un hacer posible, no hay, pues, un estatuto de voluntad que determine un yo-puedo-gestar, en el sentido de una posibilidad real (que pueda ser negada). La diferencia reproductiva del cuerpo femenino no es una acción sino una función que, sin embargo, determina los valores prácticos de la feminidad.

Antes de la — tardía- tipificación de la violación como un crimen de guerra específico, los delitos sexuales se incluían bajo la categoría de tortura. La definición de tortura que aporta Bergoffen es especialmente útil para el caso, pues basa su diferencia en el tipo de capacidades o potencialidades contra las que atenta cada forma de violencia corporal (tortura, violación, esclavitud), permitiéndonos analizar con precisión los mecanismos de explotación de cada uno. Su descripción de la violación remite el acto a las potencialidades sensuales del cuerpo de la víctima, y las determinaciones simbólicas de las circunstancias violentas, como la guerra, pero deja sin tematizar la función reproductiva como fondo de la constitución del cuerpo violentado y, por lo tanto, el foco central del acto destructivo que implica la violencia sexual. La violación busca destruir la capacidad sensual y de gozo, pero tal intención destructiva estaría ya fundada en el carácter diferencial del cuerpo femenino (porque también los cuerpos masculinos tienen estas potencias, pero no el significado comunitario que moviliza la violación en situaciones de guerra o invasión). Es decir, que el cuerpo violentado es, de entrada, un cuerpo ya ahí, disponible, históricamente constituido como a disposición del otro o para el otro, junto a otros recursos apropiables y transformables.

La constitución histórica del otro-femenino sujeta su corporalidad a una materialidad supuesta a la base de una escala ascendente, evolutiva y valorativa, que se reafirma en la violación, y se re-instituye en la violencia

\footnotetext{
${ }^{34}$ Ibid., p. 391.
} 
sexual, aun más visiblemente en la instrumentación de la violación como arma de guerra; tal uso del abuso sexual implica, como señala Bergoffen, la movilización de una simbólica asociada al género y la intimidad, en el nivel más visible, pero arraigada en lo más profundo en la diferencia material del cuerpo femenino. En tales circunstancias la violación exhibe el estatus económico del cuerpo femenino, su constitución como un recurso comunitario, simbólico y material.

El valor comunitario del cuerpo femenino y la construcción histórica de la reproducción, han llevado la sexuación identitaria del cuerpo-otro del plano o la esfera de la intimidad absoluta (como la capacidad de libre desplazamiento o de disfrute sensual del cuerpo propio) del yo, al plano de la pasividad, del yo dormido. Se diría, entonces, que los cuerpos femeninos son violables porque esas capacidades que la violación busca destruir han sido despojadas - históricamente- de su carácter de potencias de un yo y subsumidas como funciones de la naturaleza.

La reproducción ha sido históricamente confinada a una región ambigua y peligrosa, es una dimensión que pertenece radicalmente al plano de la naturaleza y se inserta en ella, exactamente en el mismo grado en el que pertenece originariamente al plano de lo social; esta ambigüedad se resuelve en la continuidad que el mito narra u ordena en el relato de la violación originaria: no todo comienza en un parto sino en una violación o algún estupro incestuoso.

La procreación es la primera dimensión regulada de la 'animalidad' y es fundante, por tanto, del orden cultural y humano. La "disponibilidad» del cuerpo-otro implica la reproducción como el determinante absoluto de la identidad y no como capacidad o potencialidad del yo. Se trata de reconocer los límites de la voluntad desde la situación corporal. Y la voluntad, en términos concretos, toca a todos los niveles, directa o indirectamente, a través de actividades sedimentadas en pasividades, o de resistencias directas a la fuerza del impulso o la instintividad corporal. También la percepción es constituida por el yo en su estilística sexuada. Si la reproducción es potencia o capacidad del yo, como toda potencia o capacidad de su cuerpo como su haber, debe primar, también en la reproducción, una voluntad que ya no es solamente una voluntad germinal, sino una voluntad plenamente yoica, es decir, de un yo activo y despierto, un «yo puedo» que se niega en la violación.

La disponibilidad de los cuerpos femeninos está determinada por su propia materialidad; el violador se apropia de la sensualidad del otro para destruirla, pero lo hace porque esta sensualidad se ha asumido como más 
vulnerable, más aguda, ya fundada en la diferencia reproductiva. La violación no destruye la capacidad reproductiva del cuerpo-otro, sino que instituye una negativa definitoria de la voluntad sobre tal capacidad diferencial; destruye la voluntad del cuerpo-otro.

\section{Vaciamiento espiritual de la carne}

Fue ilustre por su belleza Cénide, la hija de Elato, la más hermosa doncella de Tesalia, y tanto en las ciudades vecinas como en las tuyas (pues era paisana tuya, Aquiles) codiciada en vano por los deseos de muchos pretendientes... Y Cénide no consintió en contraer matrimonio alguno y, disfrutando de una retirada playa, sufrió la violación del dios del mar (...) y cuando Neptuno gozó del reciente amor dijo "¡Te está permitido que tus deseos estén libres de rechazo: elige lo que deseas!”... Cénide dice: "Esta injuria produce un gran deseo, no poder soportar nada semejante: concédeme no ser mujer: me habrás garantizado todas las cosas." 35

Cénide le pidió al Dios que la convirtiera en un hombre invulnerable, y sus últimas palabras fueron pronunciadas con voz grave, la voz varonil de Céneo (en quien la convirtió Neptuno), uno de los Argonautas que acompaña a Jasón en su búsqueda del vellocino de oro. La última noticia que tenemos de Céneo, es que murió, en una lucha entre lápitas y centauros -los violadores.

Lo que más nos importa del relato de Cénide es la respuesta lapidaria que da a su verdugo; un "no quiero que esto, la violación, vuelva a pasar jamás" como equivalente a desear no ser mujer, es decir, que, pese al arrepentimiento de su victimario ella sabía que iban a violarla una vez más, otra vez, alguien más, hombre o inmortal alguien la iba a 'tomar' sin que ella pudiera defenderse. Cénide descubría que su vulnerabilidad era la condición encarnada de su género. Dejar de ser mujer era equivalente a ser invulnerable a eso, a esa clase de humillación. Una dimensión de sentido de ser mujer había quedado ratificado, grabado a fuego en la violación.

Este es el mensaje de Cénide, que ser mujer equivale a ser vulnerable a una violación, ser un cuerpo disponible. Reconocerse en la vulnerabilidad es (en las condiciones reafianzadas por la violación) reconocerse mujer. Hablamos de las determinaciones que la violación instituye para el sí mismo de la víctima. Vulnerabilidad, en este estrechísimo contexto, no significa nada

${ }^{35}$ Ovidio, Metamorfosis, Madrid, Cátedra, 2015, p. 638 /1437. Trad. Consuelo Álvarez y Rosa Ma. Iglesias. 
más que el saber-se a disposición del otro, a 'merced' del otro en el plano de una experiencia disruptiva y violenta. ${ }^{36}$

La mediación identificante de la víctima es la vulnerabilidad que determina toda su identidad corporal. Cénide sabe que volverá a pasar, esa conciencia de su determinación, arrojada en su cuerpo, es lo que instaura el acto violento, la reafirmación del sí mismo de la víctima en la vulneración, o su negación en la humillación.

La violación instaura la disponibilidad en el corazón mismo de la constitución sexuada del cuerpo propio y sus valores espirituales sedimentados. El otro femenino, el de la diferencia reproductiva es, por esa misma determinación (otra capacidad que negar o destruir en la violencia), el sí mismo vulnerable. La vulnerabilidad implica el reconocimiento radical, carnal, de la disponibilidad que se afirma, en carne propia, en la violación; esto significa que la disponibilidad no es una 'mera' idea, sino una experiencia, un significado encarnado por la fuerza en la violación.

Neptuno no sólo destruye capacidades corporales (también en el núcleo de la identidad personal) sino que, más allá, instituye un rasgo, una determinación inherente a la auto-constitución de la identidad personal de Cénide, la vulnerabilidad co-originaria de su condición de género. Por eso dejar de ser mujer equivale a ser invulnerable a eso, al crimen que Neptuno perpetró. Que haya muerto en una pelea contra los centauros (estupradores originarios) solo prueba que, en efecto, su invulnerabilidad abarcaba sólo esa dimensión que concentra, sin embargo, su personalidad entera o su ser mujer: el ser violable. Los centauros no violaron a Céneo, él murió en la batalla contra ellos.

La violación sexual, podría entonces pensarse como trasgresión física que 'espiritualiza' la carne en su 'desespiritualización' o su vaciamiento. La disponibilidad de los cuerpos femeninos permite esta negación violenta de la voluntad del cuerpo, su cosificación, por las condiciones profundas del significado de la carne femenina y por la ambigüedad de la voluntad

${ }^{36}$ Es probable que sea todavía necesario repensar el concepto de "vulnerabilidad" como el más apropiado o preciso para designar la posición del cuerpo femenino en esta esfera antropológica. Parece demasiado abierto todavía ese saber-se a merced del otro, que no precisa la profundidad de esa conciencia corporal-femenina. Por otro lado, la estrecha relación entre vulnerabilidad y corporalidad que se explota en la violencia hace de este concepto el más adecuado en este contexto. "Hay una marca simbólica y un límite material entre lo humano y lo infrahumano, fundado en límites impuestos sobre la higiene que funcionan como elementos ingredientes del contenido autoperceptivo de la dignidad." Venebra, M., "El mal y las técnicas de envilecimiento: fenomenología del cuerpo torturado", en Investigaciones Fenomenológicas, No. 16, Madrid, SEFE, p. 128. 
de un yo referido a las funciones específicas de su diferencia identificante; tales condiciones posibilitan la negación violenta del estupro que a su vez funciona como instauración, cierre y reinicio del ciclo de vaciamiento espiritual de la corporalidad femenina, de su estabilización. La violación sexual es una institución en la medida en que instituye no sólo un significado de los cuerpos sino un régimen de sentido (campos semánticos enteros) de la materialidad, la corporalidad y la vida.

La violación sexual es una organización originaria -experiencial一 del orden de los cuerpos como disponibles y no disponibles. Podemos decir que la violación es la otra cara de la prohibición del incesto; lo que la prohibición del incesto contiene o refrena es la violación sin reglas.

Todo comienza con una violación. La violación está en el límite, que acecha porque participa del caos y el rompimiento del orden, tanto como de su génesis e instauración. Si efectivamente la prohibición del incesto es la primera norma, la que da origen a lo social, y toda norma representa la contención de una conducta de hecho amenazante, patente o latentemente, en la comunidad, esa conducta es la violación; la regulación social ha consistido entonces en un ordenamiento jerárquico de la disponibilidad y su legitimación en la norma misma. La violación es originaria en dos dimensiones, primero porque reafirma un orden de los cuerpos, reactiva (significativamente) en el acto violento la disponibilidad del cuerpo femenino, cuyo sentido se hunde en las bases de lo social, en la ordenación simbólica originaria de los cuerpos y del mundo con otros. Segundo, porque este orden es experiencial, ese es el sentido de la 'institución', como lo que se constituye en la experiencia. El vaciamiento espiritual implica la instauración de la vulnerabilidad como determinante de la identidad femenina y la violación sexual es la signatura de este régimen de sentido. Quiero decir que la violencia sexual implica un marco de significados que la hace posible.

Ser mujer equivale a ser posiblemente violada, en algún momento de la vida, de alguna manera, y esta conciencia se agudiza en regímenes anárquicos o autoritarios - bajo la ebriedad que representa la flexibilización permisiva de la norma. ${ }^{37}$ La disponibilidad de mi cuerpo, su significado de carne disponible se reactiva en la violación, es decir, la cosificación sexual que el estuprador lleva a cabo en el acto violento es la consecuencia de la constitución histórica del cuerpo de la víctima como ahí disponible, como un recurso. Esta construcción histórica de significado tiene su núcleo, como hemos visto, en la simbólica de la materialidad del cuerpo femenino, que

\footnotetext{
${ }^{37} \mathrm{La}$ ebriedad de los centauros representa el desorden político en la simbólica del mito.
} 
arraiga en sus primeras representaciones históricas o espirituales y se manifiesta en la alienación violenta de la voluntad yoica sobre las 'capacidades' diferenciales de su propio cuerpo.

\section{Conclusiones: La violación que origina}

La violación es originaria porque origina un orden de sentido en el que se funda una organización de los cuerpos; afirma la pasividad femenina como principio constituyente de su corporalidad, y la negación de su voluntad por la violencia. La violación sexual es posible porque los cuerpos femeninos se constituyen históricamente como cuerpos disponibles y esta condición se explicita violentamente bajo ciertas condiciones políticas de caos y/o contradicción. Un régimen anárquico o acéfalo puede propiciar una mayor explotación de tal condición, pero también los regímenes estatales que afirman la regulación política de la diferencia reproductiva del cuerpootro. La regulación legal del aborto, por ejemplo, expone abiertamente la disponibilidad comunitaria de la capacidad reproductiva del cuerpo-otro, y la 'necesaria' regulación política del yo-puedo, o la voluntad que le corresponde. El yo-puedo-gestar, es decir, desplegar un movimiento de mi cuerpo, interrumpirlo, se pierde de vista en un discurso que niega la voluntad vital de la madre, la voluntad sobre su propio cuerpo, y se le endosa a una parte suya no egoica, pasiva. No cabe aquí desarrollar una posición sobre las implicaciones de tal debate, baste con señalar que el análisis fenomenológico de la corporalidad nos permite penetrar por nuevas vías, experienciales, en este campo de problemas.

La disponibilidad de los cuerpos femeninos es condición a priori de la violación porque el significado histórico de su materialidad totaliza su identidad. La metafísica de la naturaleza como materia reproducible, que reposa en el fondo de este régimen de sentido, y que alcanza, según Husserl a la lógica y la ética de las ciencias, es lo que acaso toca de-construir y criticar a la filosofía.

Apelar a la definición fenomenológica del cuerpo vivido para explicar las fuentes de la violación sexual, implica reconocer que la carne no totaliza a la persona, que lo conciencial y lo corporal son al final lo más semejante que hay a un cometa y su estela. Si la violación se basa en una significación naturalizante, cosificante de la persona (dentro de un marco de sentido sedimentado), la redignificación tendrá que apelar a la reinstauración de la voluntad y la libertad yoica como no determinadas por la materialidad 
del cuerpo, o a la materialidad del cuerpo como carne espiritual; esto es, buscará reinstaurar la identidad y los valores de la persona más allá de la tendencia totalizante de la corporalidad sobre la propia identidad. Sí, (fenomenológica o experiencialmente) soy mi cuerpo, pero además tengo un cuerpo y soy más que mi cuerpo.

\section{Bibliografía}

Arendt, Hannah, La condición humana, Barcelona, Paidós, 2016.

Beauvoir, Simone de, El segundo sexo, México, Penguin, 2012.

Bergoffen, Debra B., "Exploiting the Dignity of the Vulnerable Body: Rape as a Weapon of War" en M. Staudigl, Phenomenologies of Violence, Leiden-Boston, Brill, 2014.

Butler, J., Cuerpos que importan. Sobre los limites materiales y discursivos del "sexo", Barcelona, Paidós, 2002. Trad. Alcira Bixio.

De la Fuente, Beatriz, "La universalidad en las representaciones de la figura humana", Arqueología Mexicana, No. 65, enero-febrero de 2004, pp. 12-15.

Eliade, Mircea, Lo sagrado y lo profano, Barcelona, Paidós, 1998.

Eliade, Mircea, Tratado de historia de las religiones, México, Biblioteca Era, 2001. Trad. Tomás Segovia.

Héritier, Françoise Masculino / Femenino. El pensamiento de la diferencia, Barcelona, Ariel, 1996. Trad. Vicente Villacampa.

Husserl, Edmund, "El espíritu común (Gemengeist) I y II (1921). Obra póstuma”, Universidad de Sevilla. Trad. César Moreno Márquez, en Themata. Revista de Filosofía, Universidad de Sevilla, No. 4., 1987, pp. 131-158.

Husserl, Edmund, "El origen de la geometría", en Estudios de filosofía, No. 4. Pontificia Universidad Católica del Perú. Instituto Riva-Agüero, 2000, p. 36/368. Trad. Rosemary Rizo-Patrón de Lerner y Jorge Arce. Original: Beilage III, [Ursprung der Geometrie] zu $\mathbb{~} 9^{\mathrm{a}} 1$, Hua VI, pp. 365-386.

Husserl, Edmund, Ideas relativas a una fenomenología pura y una filosofía fenomenológica, Libro II, Investigaciones filosóficas sobre la constitución, México, FCE, 2005, Trad. Antonio Zirión Quijano.

Husserl, Edmund, Meditaciones cartesianas, México, FCE, 2005. Trad. Miguel García Baró.

Miano, Borruso Marinella, Hombre, mujer y muxe' en el Istmo de Tehuantepec, México, CONACULTA-INAH-Plaza y Valdés, 2002. 
Ovidio, Metamorfosis, Madrid, Cátedra, 2015. Trad. Consuelo Álvarez y Rosa Ma. Iglesias.

San Martín, J. "La fenomenología y el otro. La fenomenología encarando al siglo XXI" en Acta Mexicana de Fenomenología. Revista de investigación filosófica y científica, CEMIF, No. 1., 2015.

Venebra, M., "El mal y las técnicas de envilecimiento: fenomenología del cuerpo torturado", en Investigaciones Fenomenológicas, No. 16, Madrid, SEFE, pp. 109-133.

Zoja, L., Los centauros. Los orígenes de la violencia masculina, México, FCE, 2018. 